\title{
Uusioersily
}

\section{Dynamics of Hydrogen Flame Self-Extinction in a Vented Enclosure}

Molkov, V., Shentsov, V., Brennan, S., \& Makarov, D. (2013). Dynamics of Hydrogen Flame Self-Extinction in a Vented Enclosure. In Unknown Host Publication University of Maryland. https://doi.org/10.3850/978-981-075936-0_14-03

Link to publication record in Ulster University Research Portal

\section{Published in:}

Unknown Host Publication

Publication Status:

Published (in print/issue): 10/05/2013

DOI:

10.3850/978-981-07-5936-0_14-03

\section{Document Version}

Publisher's PDF, also known as Version of record

\section{General rights}

Copyright for the publications made accessible via Ulster University's Research Portal is retained by the author(s) and / or other copyright owners and it is a condition of accessing these publications that users recognise and abide by the legal requirements associated with these rights.

\section{Take down policy}

The Research Portal is Ulster University's institutional repository that provides access to Ulster's research outputs. Every effort has been made to ensure that content in the Research Portal does not infringe any person's rights, or applicable UK laws. If you discover content in the Research Portal that you believe breaches copyright or violates any law, please contact pure-support@ulster.ac.uk. 


\title{
Dynamics of Hydrogen Flame Self-Extinction in a Vented Enclosure
}

\author{
Molkov, V., Shentsov, V.*, Brennan, S., and Makarov, D. \\ Hydrogen Safety Engineering and Research Centre (HySAFER), \\ University of Ulster, Shore Road, Newtownabbey, BT37 OQB, UK \\ *Corresponding author email: shentsov-v@email.ulster.ac.uk
}

\begin{abstract}
The phenomenon of hydrogen jet flame self-extinction in an enclosure with one vent is simulated numerically for the first time. The eddy dissipation concept model of combustion with a full chemistry scheme is applied along with the renormalization group theory for turbulence modelling within RANS approach. The analysis of temporary profiles of temperature and species (hydrogen, oxygen, hydroxyl, water) concentrations in the numerical experiment, as well as velocity through the vent, shed a light on the dynamics of under-ventilated hydrogen fire the self-extinction process in the enclosure with one horizontal vent located under the ceiling. The self-extinction is a process rather than an instance. The analysis of under-ventilated fire based on parameters averaged throughout the enclosure can give a good indication of the moment when combustion essentially reduces due to lack of oxygen, yet it can mislead in interpretation of the moment when combustion is fully ceased. It is shown that the pressure peaking phenomenon is more pronounced for jet fire compared to unignited release from the same source (by factor 100 in this particular experiment, i.e. about $300 \mathrm{~Pa}$ and $3 \mathrm{~Pa}$ respectively). The separation distances from the enclosure are estimated for this indoor fire scenario. The maximum length of hot gases jet escaping the enclosure was about twice of the enclosure size. The simulations demonstrated a complex flow dynamics through the vent in both directions during the self-extinction process. This is thought due to the interaction between processes of sustained hydrogen leak, combustion, and heat transfer to the enclosure walls. The separation distances from the enclosure are estimated for indoor fire scenario.
\end{abstract}

KEYWORDS: Self-extinction, hydrogen flame, under-ventilated fire, numerical experiment, species concentrations.

\section{INTRODUCTION}

Indoor use of hydrogen and fuel cell systems poses a number of safety issues in case of unscheduled leak. One possible accident scenario is hydrogen jet fire in an enclosure. Knowledge about hydrogen jet flame behaviour in confined space is practically absent. Before safety strategies and engineering tools for indoor hydrogen fires are developed underpinning physical phenomena have to be understood. This paper is focused on understanding of under-ventilated hydrogen fire dynamics, and especially on the process of flame self-extinction. The study includes a numerical experiment exploiting the most advanced modelling techniques and its analysis.

The CFD solver of the ANSYS FLUENT software based on Reynolds Averaged Navier-Stokes (RANS) equations is applied. The eddy dissipation concept [1] is exploited for simulation of combustion with a full chemistry scheme, and the renormalization group theory [2] is used for the sub-grid scale modelling of turbulence. A similar approach has been successfully applied recently for the simulation of spontaneous ignition of a sudden hydrogen release in a T-shaped pressure relief device [3]. However, compared to the study of spontaneous ignition the reaction scheme for indoor fire simulations excludes $\mathrm{NO}_{\mathrm{x}}$ chemistry. Previous work [3] can be considered as an implicit validation of the approach and sub-models in absence of hydrogen indoor fire experiments planned for 2013-2014 within the HyIndoor project (www.hyindoor.eu). 


\section{NUMERICAL EXPERIMENT DESCRIPTION}

The simulations were carried out to investigate dynamics of self-extinction phenomenon in a fuel cell like enclosure of size $L x W x H=1 \times 1 \times 1 \mathrm{~m}$ with one horizontal vent of size $H x W=0.03 \times 0.3 \mathrm{~m}$ located in a wall centre just under the ceiling. Hydrogen leak mass flow rate was $1.085 \mathrm{~g} / \mathrm{s}$, which corresponds to flow velocity $600 \mathrm{~m} / \mathrm{s}$ at temperature $273 \mathrm{~K}$ through a pipe of $5.08 \mathrm{~mm}$ internal diameter. This is a characteristic mass flow rate for a $50 \mathrm{~kW}$ fuel cell. The leak from the pipe was directed vertically upward. The pipe exit was $10 \mathrm{~cm}$ above the floor. Hydrogen was released in the numerical experiment from a boundary that is a cross-section of the pipe located $5 \mathrm{~cm}$ within the pipe with the uniform sub-sonic velocity of $600 \mathrm{~m} / \mathrm{s}$. The pipe was initially filled in by air. The composition of air in the simulations is taken as $20.7 \%$ by volume of oxygen and $79.3 \%$ by volume of nitrogen. Initial temperature of air was $293 \mathrm{~K}$ throughout a calculation domain, i.e. 20 degree higher than leaking hydrogen. The mass flow rate and the temperature of leaking hydrogen were both kept constant during the simulations.

The vent size was pre-calculated using theory [4] to ensure that there is no air ingress into the enclosure through the vent when the enclosure is fully occupied by hydrogen in a case of unignited release, and that the pressure peaking phenomenon [5] does not generate overpressure above $10 \mathrm{kPa}$ that all civil structures can withstand without destruction (windows can be broken in some cases by pressures as low as $2 \mathrm{kPa}$ ). The overpressure due to the pressure peaking phenomenon for the unignited release in the enclosure was estimated as insignificant $3 \mathrm{~Pa}$.

The calculation domain was a hexahedron of size $L x W x H=7 \times 6 \times 4$ m that included the enclosure and free space around. The enclosure walls were "made" of aluminium with thickness of $20 \mathrm{~mm}$. Heat transfer to the enclosure walls, ceiling and floor was simulated by means available in ANSYS FLUENT. The simulations were performed for $145 \mathrm{~s}$ of real time after the beginning of the release, including stages of the short unignited release, the numerical ignition of the hydrogen jet, the initial stage of combustion that is "well-ventilated", the under-ventilated jet fire with flame self-extinction, and finally the stage of non-reacting hydrogen release into the hot combustion products and its cooling.

The block-structured hexahedral grid generated by ICEM CFD 13.0 is shown in Fig. 1. The calculation domain counts a total number of control volumes (CVs) 1,530,987. The hydrogen inflow boundary was a cross-section area of $45 \mathrm{CVs}$ and $450 \mathrm{CVs}$ in total within the pipe. The total number of CVs in the enclosure is 229,746 . The wall thickness is resolved with 4 cells and there are 73,274 CVs inside walls. The number of CVs along the vent width is 33, and along the vent height is 5 (depth of the vent is the same as walls - 4 cells). There are $660 \mathrm{CVs}$ in the vent.

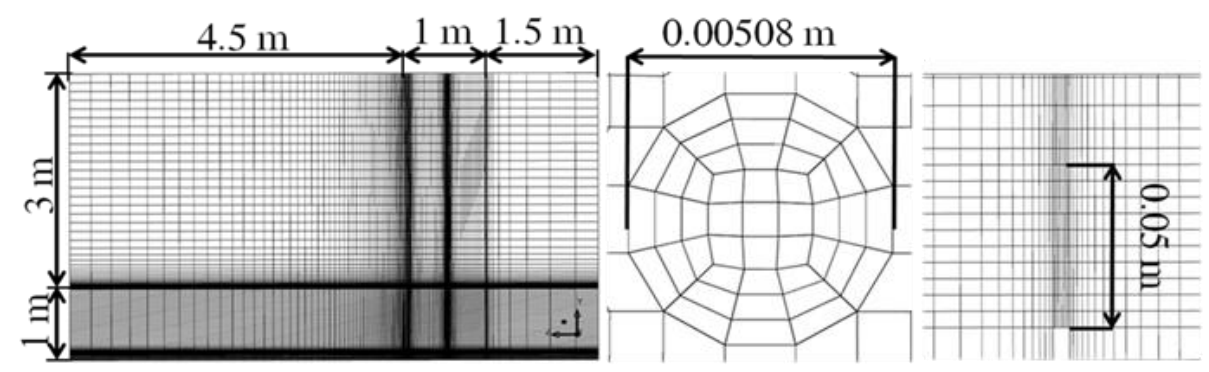

Figure 1. Calculation domain and computational mesh: general view (left), pipe cross-section (centre), pipe side view (right). 


\section{RESULTS AND DISCUSSION}

\section{Unignited release stage and numerical ignition}

The unignited release stage had continued in this numerical experiment for the first $0.3 \mathrm{~s}$. The contours of hydrogen jet development during this period are shown in two first snapshots in Fig. 2 (top). Numerical ignition was initiated at $0.3 \mathrm{~s}$ after the beginning of the release when the initial hydrogen jet reached about $80 \%$ of the enclosure height (snapshot " $0.3 \mathrm{~s}$ " in Fig. 2, top).
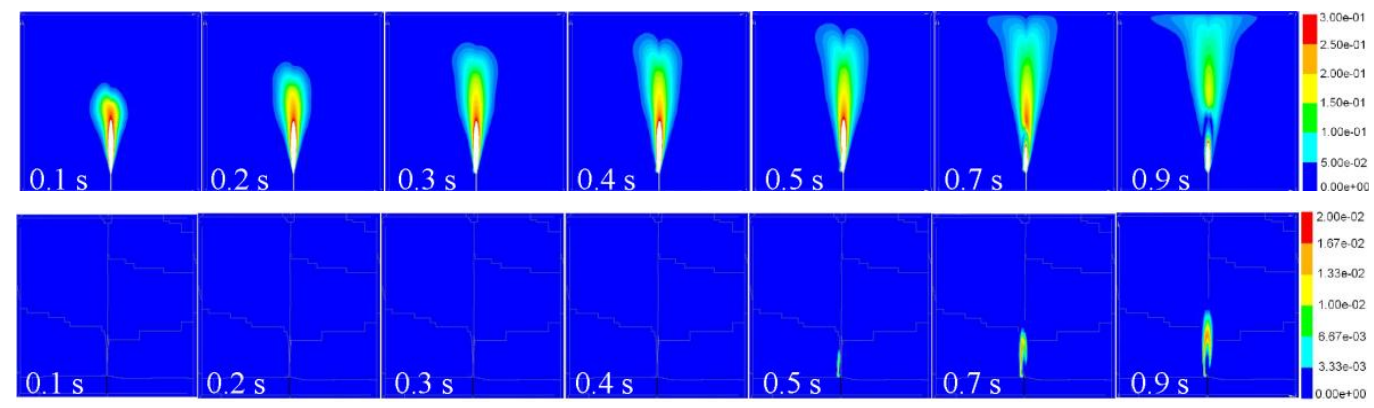

Figure 2. Contours of hydrogen (top) and hydroxyl (bottom) mole fractions in 2D slice along the pipe axis.

The duration of numerical ignition was $0.2 \mathrm{~s}$ : from $0.3 \mathrm{~s}$ to $0.5 \mathrm{~s}$. The numerical ignition source was a patch with temperature $3000 \mathrm{~K}$ over the zone $L x W x H=1 \times 0.25 \times 1 \mathrm{~cm}$ that occupies 62 control volumes (CVs) and touches the pipe on its left side (see Fig. 2, top, snapshots " 0.3 s" and after). The zone was chosen to include a region with near stoichiometric hydrogen-air mixture to facilitate the numerical ignition. Snapshots " $0.7 \mathrm{~s}$ " and " $0.9 \mathrm{~s}$ " in Fig. 2 (top) clearly demonstrate that the flow is affected by the initiated combustion.

Figure 2 (bottom) shows areas within the enclosure with high concentration of hydroxyl where combustion takes place. The mole fraction of hydroxyl of about 0.01 is usually accepted as associated with the combustion zone at normal atmospheric conditions [6]. There is a clearly seen zone with no hydrogen in the jet at snapshot " $0.9 \mathrm{~s}$ " (Fig. 2, top) when the reaction zone is already established and consumes hydrogen (Fig. 2, bottom). There is a flammable non-uniform hydrogen-air cloud above the reaction zone at this moment with the highest concentration of about $16 \%$ of hydrogen by volume in air. The established non-premixed turbulent flame does not present an ignition source for the premixed hydrogen-air cloud above the flame, which would be expected to deflagrate in fractions of seconds if ignited. This is in agreement with the knowledge that hydrogen jet flame tip is located where the concentration in unignited jet from the same leak source decays to $8-16 \%$ by volume, and that non-premixed turbulent combustion does not propagates downstream to areas with smaller hydrogen concentrations [7].

However, a presence of an ignition source of sufficient energy in this initial premixed hydrogenair could probably initiate deflagration of this non-uniform mixture created during the short $(0.3$ s) period of unignited release. In $2 \mathrm{~s}$ after the release initiation the flammable hydrogen-air cloud dissipates below the lower flammability limit (see Fig. 3, top left). This implies that spontaneous ignition of a sudden hydrogen release by the diffusion mechanism [3] could be an effective technique to reduce pressure effects and thus negative consequences of unscheduled indoor release of hydrogen. The validity of this safety strategy has to be proved by further research.

\section{Jet flame development}

Figure 3 shows the dynamics of temperature and mole fractions of hydrogen, oxygen, and water within the enclosure during the first $60 \mathrm{~s}$ of the process. The flame length grows after the ignition source was switched off (see also Fig. 4). High temperature reaches the ceiling at about $2 \mathrm{~s}$, combustion products start to descend at about $4 \mathrm{~s}$, and after 10-15 s practically the whole volume 
of enclosure is occupied by hot products creating intolerable temperature conditions. During the first $10 \mathrm{~s}$ of combustion the temperature reached the maximum value above $2200 \mathrm{~K}$, and began to decrease after this time due to dilution of the combustion zone by entrained combustion products.

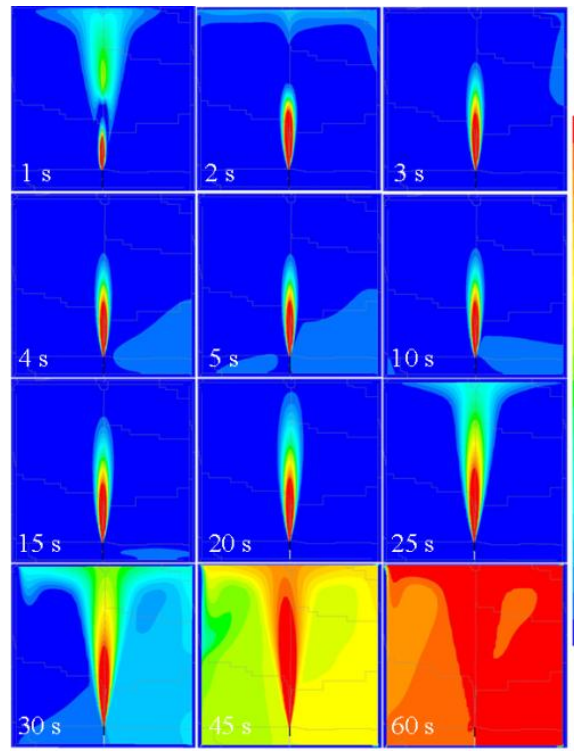

Hydrogen mole fraction: $0.00-0.30$
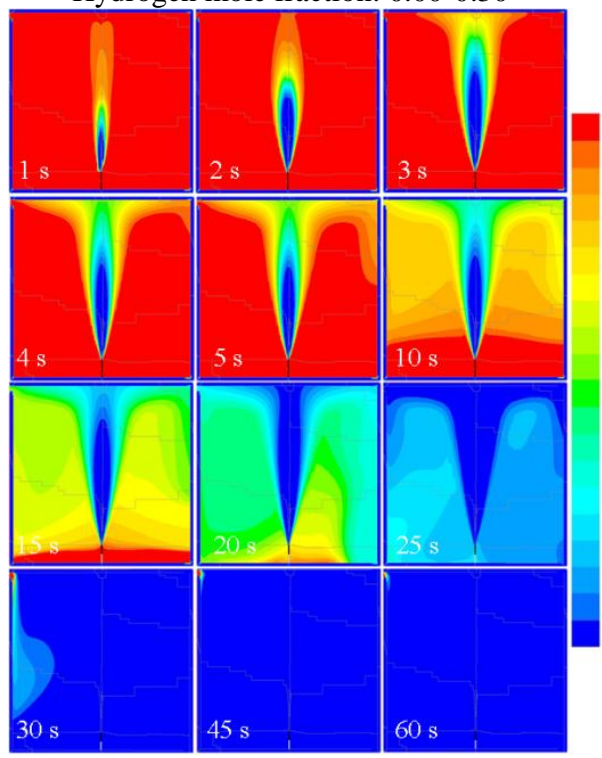

Oxygen mole fraction: $0.00-0.20$

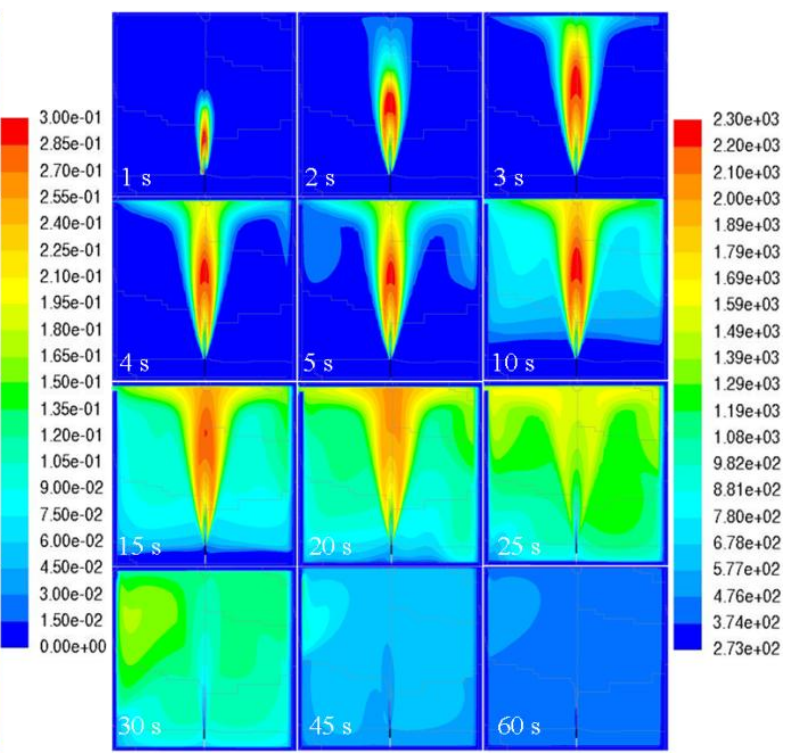

Temperature: 273-2300 K

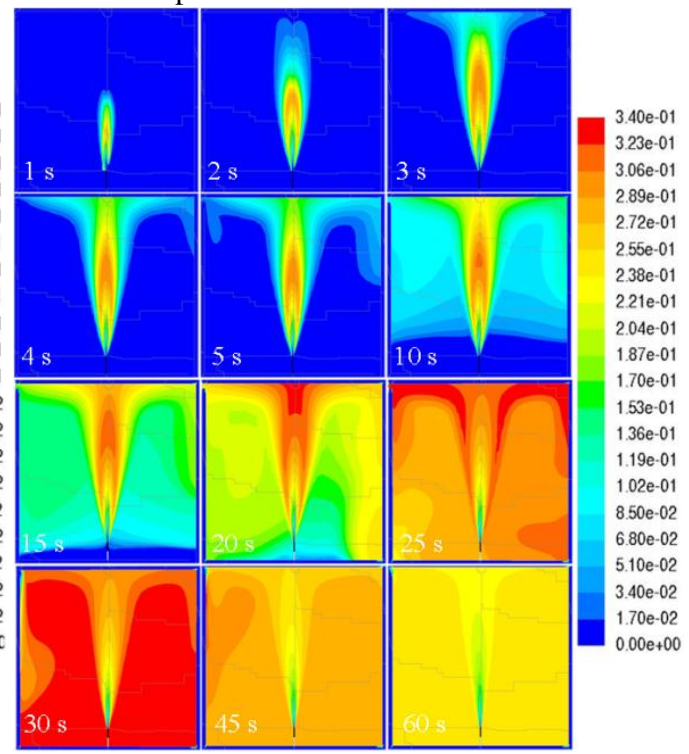

Water mole fraction: $0.00-0.34$

Figure 3. The simulated dynamics of hydrogen flame self-extinction in the enclosure with one vent. From left to right: hydrogen mole fraction (in the range 0.00-0.30), temperature (273-2300 K), oxygen mole fraction $(0.00-0.20)$, water vapour mole fraction $(0.00-0.34)$.

Numerical simulations demonstrated that hydrogen flame grows until about $10 \mathrm{~s}$ when there are distinct areas of hydroxyl $(\mathrm{OH})$ mole fraction about 0.01 (Fig. 4, left). Then the hydroxyl mole fraction starts to decrease and practically vanishes at the central (along the pipe) $2 \mathrm{D}$ cross-section of the enclosure at time about $45 \mathrm{~s}$ (Fig. 4, right). 
Hydrogen mole fraction distribution in the enclosure is quasi-steady from about $4 \mathrm{~s}$ to $10 \mathrm{~s}$ (Fig. 3 , top left) when the regime of combustion is of well-ventilated fire. Hydrogen envelope and hydroxyl zone start to grow after about $10 \mathrm{~s}$ that indicates that there is not enough oxygen entrained into the hydrogen jet to complete combustion in vitiated atmosphere at the same flame length as before. Indeed, Fig. 3 (left bottom) shows that oxygen molar fraction drops practically throughout the whole enclosure at $10 \mathrm{~s}$ except a narrow region close to the floor.
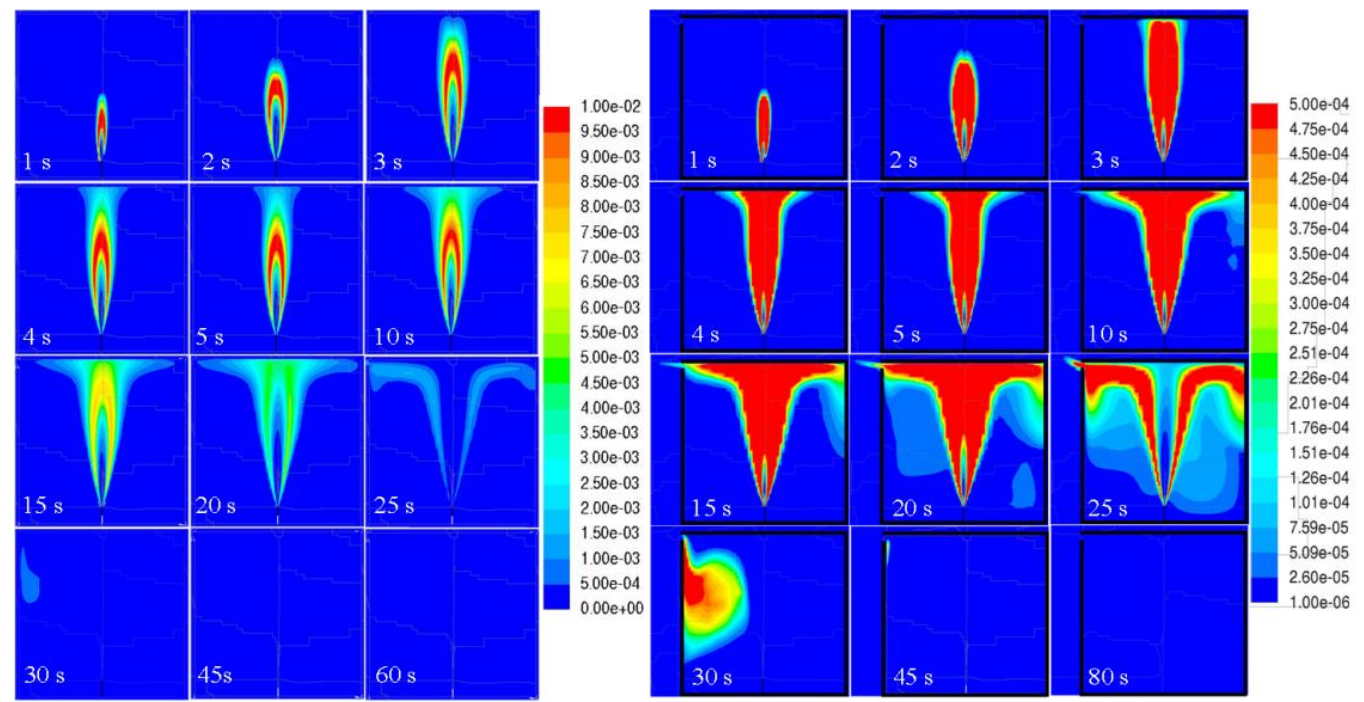

Figure 4. Contours of hydroxyl $(\mathrm{OH})$ mole fraction in a 2D slice along the pipe axis in the range: 0-0.01 (left), and 1E-06 - 5E-04 (right).

Combustion products (see water mole fraction in Fig. 3, bottom right) reach the ceiling at about 2 $\mathrm{s}$ then spread as a ceiling jet for couple of seconds. After that combustion products begin to descend and extend downward to the level of the release point at 10-15 s. The entrainment of water into combusting hydrogen jet dilutes reaction. At the same time oxygen mole fraction reduces due to combustion and lack of air intake into the enclosure through the vent (Fig. 3, bottom left).

High descending temperature (Fig. 3, top right) presents a hazard for equipment and life safety, e.g. it would impair evacuation in room-like enclosure. This must be considered when carrying out hydrogen safety engineering. The temperature throughout the enclosure is around $1000 \mathrm{C}$ at time 15-25 s. This is a characteristic temperature for fire transition to the flashover regime.

There is a potential "ambiguity" in interpretation of snapshots in Figs. 3 and 4 as follows. There is a decrease of temperature and $\mathrm{OH}$ concentration from snapshot " $25 \mathrm{~s}$ " to snapshot " $30 \mathrm{~s}$ " yet the amount of water vapour is increased during the same period. The answer to this "ambiguity" can be partially drawn from Fig. 5 and the fact that visualisation of parameters in these figures is in 2D slice only. The maximum concentration of water in central 2D slice is at the intermediate snapshot " $27.5 \mathrm{~s}$ " rather than " $30 \mathrm{~s}$ ". It will be demonstrated below that weak reactions will continue in some isolated areas within the enclosure up to $80 \mathrm{~s}$.

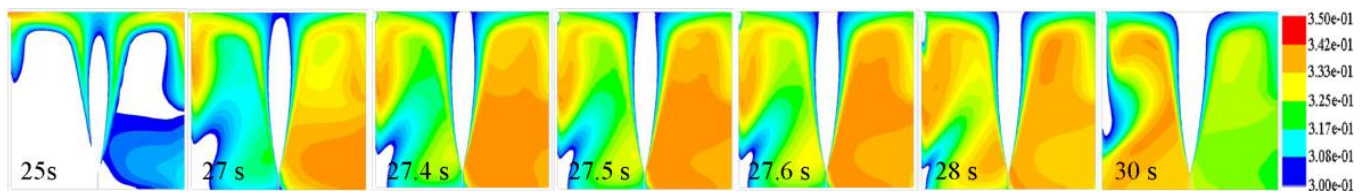

Figure 5. Contours of water mole fraction in a 2D slice along the pipe axis in the range 0.3-0.35. 


\section{Self-extinction of under-ventilated fire}

\section{Dynamics of field parameters within enclosure}

Self-extinction of hydrogen flame is not an instant process. The rate of combustion reactions is affected with time by the consumption of oxygen initially available in the enclosure, and by dilution of the reaction zone by entrained combustion products, i.e. water vapour and nitrogen.

At time $10 \mathrm{~s}$ the initial concentration of oxygen is present only in a quarter of the enclosure volume near the floor (Fig. 3, bottom right). From $10 \mathrm{~s}$ to $25 \mathrm{~s}$ the oxygen mole fraction drops from the initial value of 0.207 to less than 0.05 . This oxygen concentration is known to be insufficient to sustain hydrogen combustion in air at normal pressure and temperature. However, a different value of oxygen concentration could be characteristic for a vitiated atmosphere and elevated temperature. Figure 4 (left) shows that there are regions with small amount of hydroxyl radicals implying ceasing yet presence of reaction $(\mathrm{OH}$ is visualised in the range $0.00-0.01$ in Fig. 4, left).

Figure 4 (right) is a visualisation of hydroxyl mole fraction in the range 1E-06 - 5E-04 to "zoomin" and see regions of weak reaction in a central cross-section of the enclosure. The location of reaction zone before it ceases in this $2 \mathrm{D}$ slice is near the vent (snapshots " $30 \mathrm{~s}$ " and " $45 \mathrm{~s}$ " in Fig. 4 , right). This "late" reaction within the enclosure close to the vent is due to air ingress into the enclosure that starts at about $26.8 \mathrm{~s}$ through the lower part of the vent in its corners (Fig. 6).

Figure 6 shows horizontal velocities at the vent exit to the atmosphere. White colour indicates areas where gas flows out of the enclosure, black colour shows areas through which gas enters the enclosure, and gray colour points out regions where velocity is about zero. There is a range of velocities indicated for each snapshot. Positive limit, if any, indicates a maximum velocity of out flowing gases and negative limit, if any, indicates a maximum velocity entering the vent. For selected conditions of the numerical experiment it is not trivial that there is a period from $26.8 \mathrm{~s}$ to about $85 \mathrm{~s}$ during which gases flow in both directions through the vent or only into the enclosure (sub-period from $27.5 \mathrm{~s}$ to about $70 \mathrm{~s}$ ). This flow pattern essentially affects the underventilated fire and the self-extinction process.
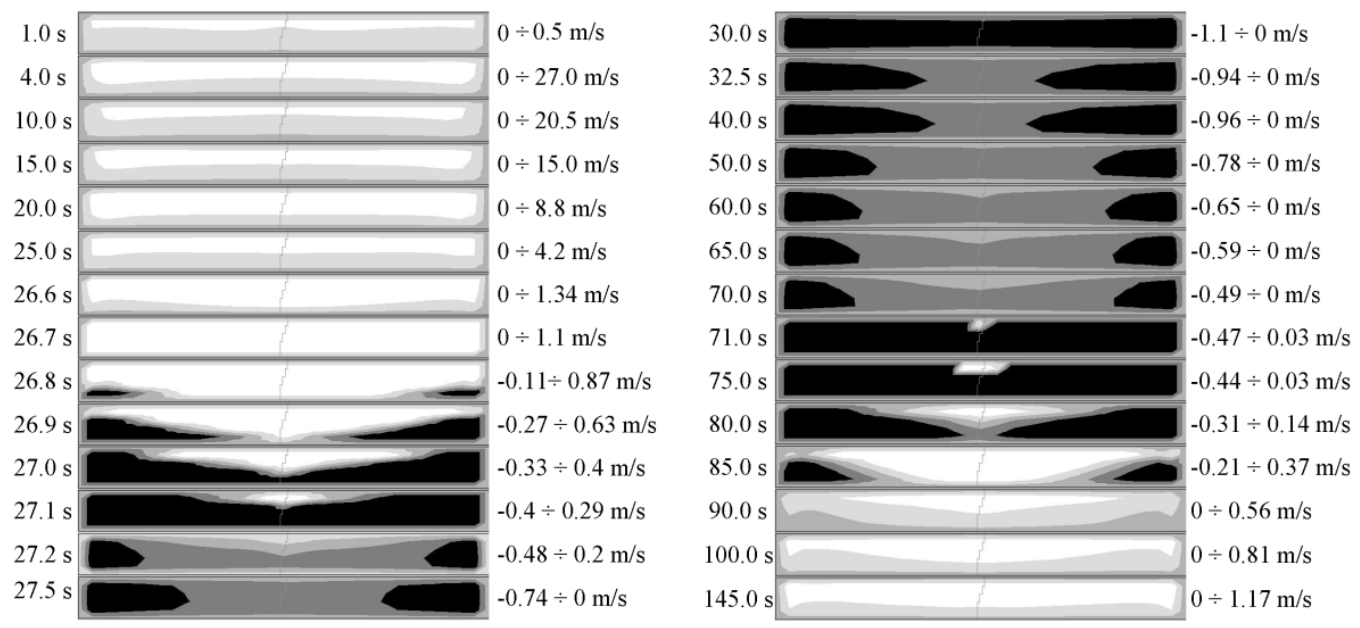

Figure 6. Velocities trough the vent: white - outflow, black - inflow.

Figure 3 shows that $60 \mathrm{~s}$ after the release there is practically no oxygen within the enclosure, temperature decreased in most of regions to 150-200 C due to sustained release of hydrogen with temperature $273 \mathrm{~K}$ and heat losses from hot gases to walls. Hydrogen concentration went up to $30 \%$ by volume at $60 \mathrm{~s}$, and water vapour concentration dropped from $25-34 \%$ by volume at $25-$ 
$30 \mathrm{~s}$ to $20-25 \%$ at $60 \mathrm{~s}$. This is due to water entrainment into the pure hydrogen jet and flow of this mixture out of the enclosure through the vent.

Figure 7 shows maximum volumetric fraction of hydroxyl radical $\mathrm{OH}$ within the enclosure as a function of time. The peak of $\mathrm{OH}$ mole fraction above 0.02 at time less than $1 \mathrm{~s}$ after the release is associated with the numerical ignition and high temperature of the patch of $3000 \mathrm{~K}$ above the adiabatic flame temperature. From about $3 \mathrm{~s}$ to about 8-10 s the mole fraction of $\mathrm{OH}$ is stabilised at a level of just above 0.01 that is a characteristic mole fraction for hydrogen combustion in air at normal conditions. This stage of combustion is similar to a free jet flame in the atmosphere as depletion of oxygen and dispersion of combustion products in the enclosure are negligible to this moment. After 8-10 s the maximum mole fraction of hydroxyl $\mathrm{OH}$ reduces monotonically to a small value of about 0.001 at about $25-30 \mathrm{~s}$ and stays at this level up to $80 \mathrm{~s}$ when it drops to zero. Thus, we can conclude that the flame self-extinction period spreads from about $10 \mathrm{~s}$ to $80 \mathrm{~s}$.

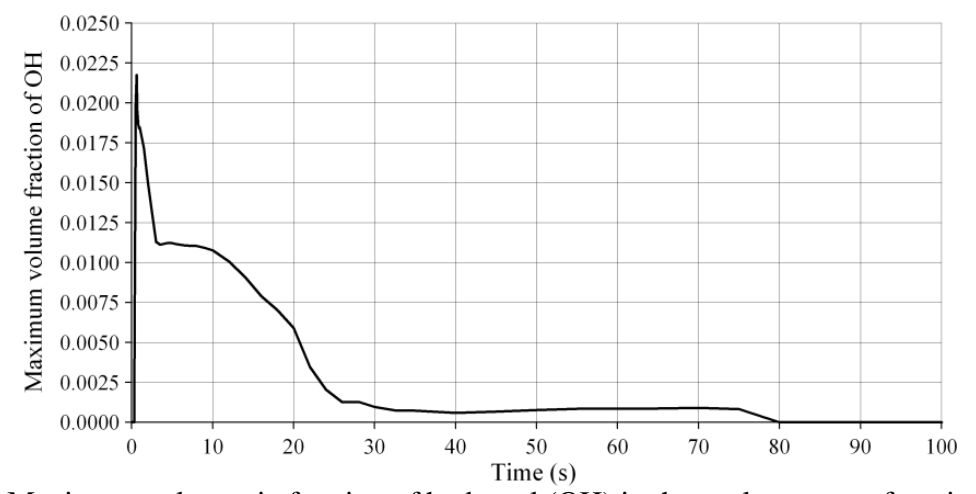

Figure 7. Maximum volumetric fraction of hydroxyl $(\mathrm{OH})$ in the enclosure as a function of time.

\section{Dynamics of averaged parameters during flame self-extinction}

Figure 8 shows average volumetric fractions of water $(\mathrm{H} 2 \mathrm{O})$, hydrogen $(\mathrm{H} 2)$, and oxygen $(\mathrm{O} 2)$. In agreement with results presented in Fig. 5 the maximum of average water concentration in the enclosure is at time $27.5 \mathrm{~s}$ after the start of the release. This time coincides with time when the average oxygen concentration decreased below the level that is able to sustain combustion (Fig. 8 , right), and hydrogen concentration starts to increase as its consumption due to combustion stopped (Fig. 8, centre). Conclusions about flame self-extinction based on average values of species in the enclosure should be done with care. Indeed, Fig. 7 shows that there are areas in the enclosure where reaction continues up to $80 \mathrm{~s}$.
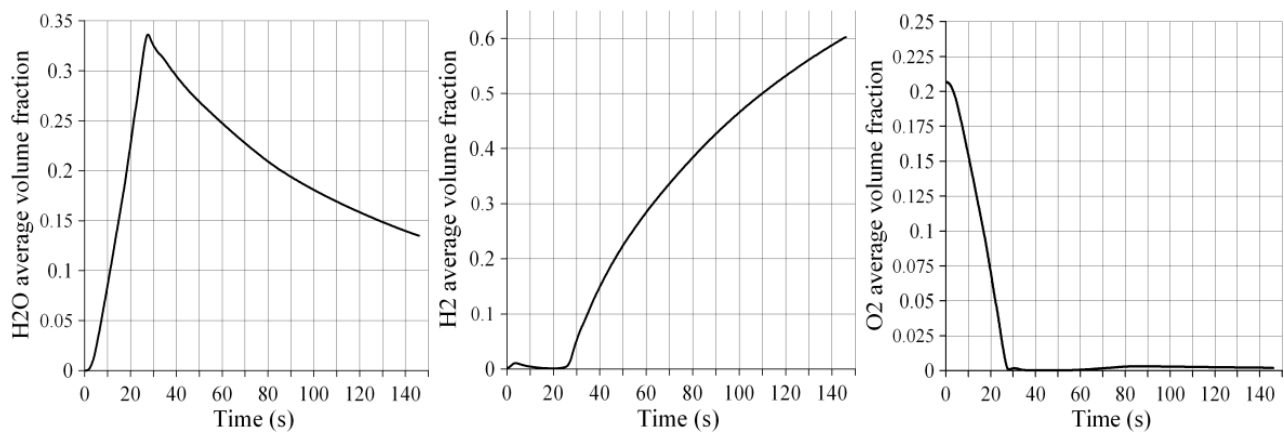

Figure 8. Species average volumetric fraction in the enclosure as a function of time: water (left), hydrogen (centre), oxygen (right). 


\section{Pressure peaking during jet fire}

It has been mentioned previously that the calculation of pressure peaking phenomenon for unignited release in the enclosure with this vent size and this mass flow rate gives overpressure of $3 \mathrm{~Pa}$ [2]. For reacting release, i.e. jet fire, a maximum simulated overpressure in the enclosure is almost 100 times higher, i.e. about $300 \mathrm{~Pa}$, for the same conditions. This pressure peak is reached at time of about $4 \mathrm{~s}$ (Fig. 9, left). The velocity of gases out of the enclosure reaches its maximum of $27 \mathrm{~m} / \mathrm{s}$ at this moment (see Fig. 6). Pressure throughout the enclosure is practically uniform during the pressure peak 1-10 s (Fig. 9, right).
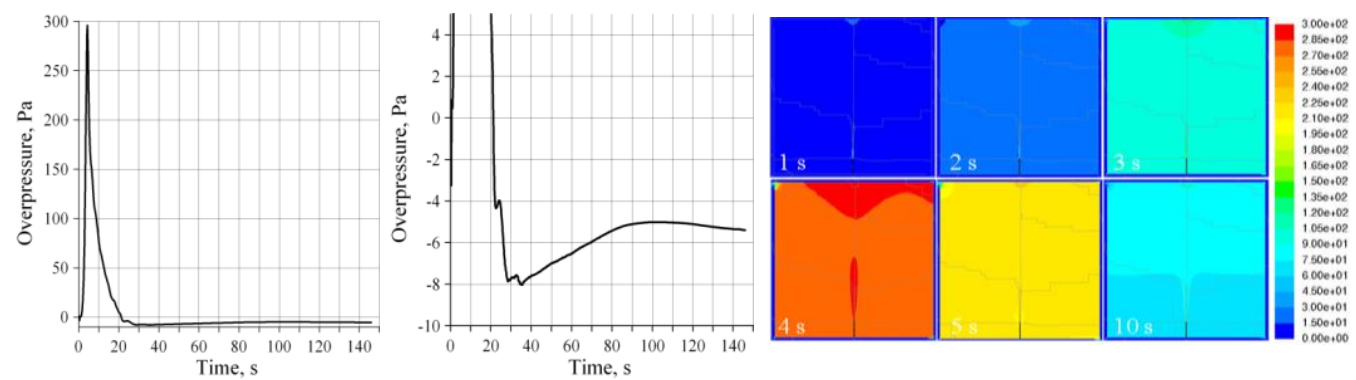

Figure 9. Average overpressure (relative to the operating pressure) within the enclosure (left, centre) as a function of time; pressure distribution within the enclosure (right).

Figure 9 (centre) shows that pressure drops to its minimum at 27-35 s when there is air intake into the enclosure (see Fig. 6). After that there is one more pressure peak of about $3 \mathrm{~Pa}$ at about $100 \mathrm{~s}$ (Fig. 9, centre) when there is no combustion any more. The averaged through the enclosure volume static pressure continues to stay below the operating pressure (initial pressure in the calculation domain without accounting for the hydrostatic pressure, $g \quad$ ). This can be explained by the fact that for this numerical experiment the neutral plane location, i.e. the height at which pressure within and outside the enclosure are equal, is just below the lower edge of the vent. This means that hydrostatic pressure at the floor level within the enclosure is lower compared to pressure at the same level outside the enclosure due to difference in density in the hydrostatic equation. The averaging of overpressure throughout the enclosure volume then gives a negative value of the order of a few Pascals (Fig. 9, centre). Yet the pressure within the enclosure above the neutral plane is higher than outside with presence of $3 \mathrm{D}$ effects as demonstrated flow pattern through the vent (Fig. 6).

\section{Weak combustion close to the vent and air ingress}

Hydrogen combustion in a form of jet flame disappears between $25 \mathrm{~s}$ and $30 \mathrm{~s}$ that can be concluded from Fig. 4. Then combustion proceeds in the form of weak reaction zone close to the vent where oxygen ingress is taking place. The region of weak reaction is formed at the vent lower edge and is spread throughout the whole width of the vent up to $50 \mathrm{~s}$. After time of $50 \mathrm{~s}$ this region degrades into two parts located at lower corners of the vent and at time about $80 \mathrm{~s}$ the combustion is fully complete in the whole domain (there is a couple of CVs with $\mathrm{OH}$ mole fraction 1E-06 at time $82 \mathrm{~s}$ ). Indeed, there are no zones with hydroxyl OH (Fig. 7) and water generation during reactions (Fig. 10). Figure 10 shows maximum net reaction rate of water generation during combustion as a function of time.

Air intake into the enclosure after $26.8 \mathrm{~s}$ (Fig. 6), which keeps the weak reaction alive, is thought mainly due to the continuing release of cold hydrogen into hot combustion products. The small almost invisible flow out of the enclosure re-starts after about $70 \mathrm{~s}$ when temperature dropped down to 100-150 C. There are flows in opposite directions through the vent up to $90 \mathrm{~s}$. From this time on the mixture of hydrogen, water and nitrogen flows out of the enclosure and there is no 
inflow. With time this would eventually form $100 \%$ of hydrogen concentration in the enclosure. At $90 \mathrm{~s}$ the temperature drops to harmless 50-55 C throughout the enclosure. However, the absence of oxygen would be a reason for asphyxiation and death would people be present in scaled up enclosure similar to that under the investigation. Approximate composition of gases at $90 \mathrm{~s}$ is: 0.19 of water vapour, 0.43 of hydrogen, and 0.38 of nitrogen. The buoyancy drives this lighter than air mixture out of the enclosure.

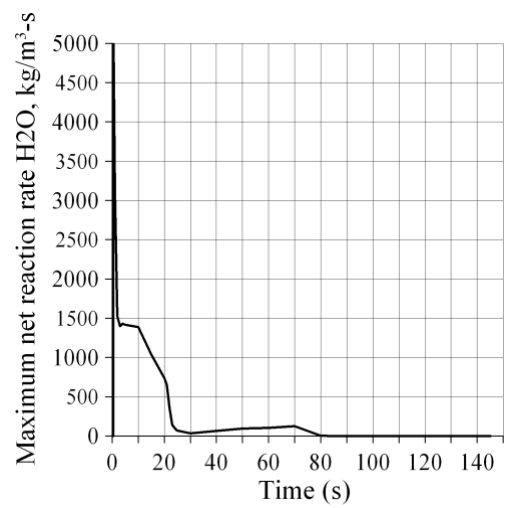

Figure 10. Maximum net reaction rate of water generation during combustion as a function of time.

\section{Separation distance from the enclosure}

Figure 11 shows the development of hot gases jet from the enclosure vent. There are three separation distances based on hot gases temperature [7]: 70 ${ }^{\circ} \mathrm{C}$ - "no harm" limit (blue colour in Fig. 11 ); $115^{\circ} \mathrm{C}$ - pain limit for 5 min exposure (green colour); $309^{\circ} \mathrm{C}$ - "death" limit due to third degree burns for a $20 \mathrm{~s}$ (red colour).

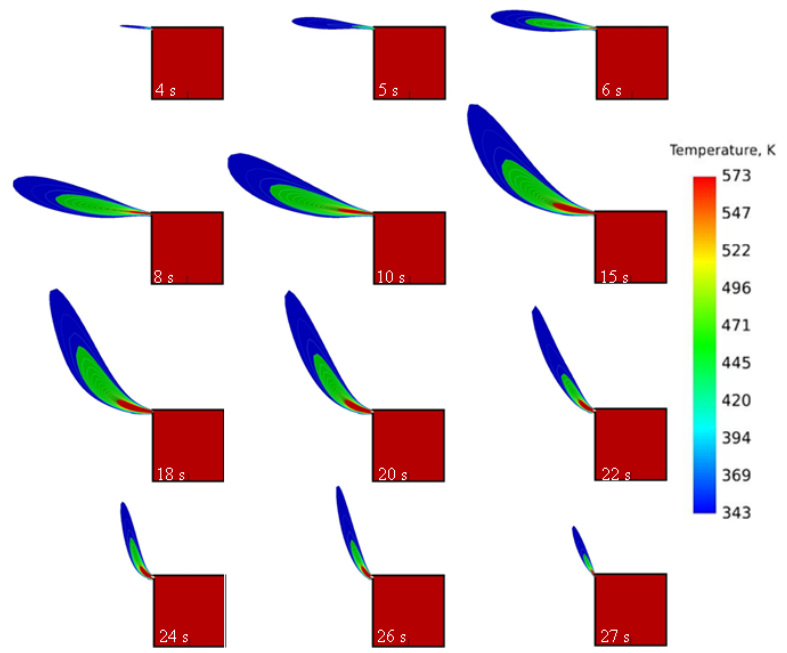

Figure 11. Contours of external jet of hot products: blue - no harm temperature $\left(70^{\circ} \mathrm{C}\right)$, green - pain limit $\left(115^{\circ} \mathrm{C}\right)$, red - third degree burn $\left(309^{\circ} \mathrm{C}\right)$.

Figure 11 demonstrates that at initial stage the jet escaping the enclosure is in momentumcontrolled regime due to higher velocity (Fig. 6) during the pressure peaking (Fig. 9, left). After the pressure peak at $4 \mathrm{~s}$ the velocity of gases flowing out of the enclosure significantly drops. Hot products and hydrogen are driven out of the enclosure by buoyancy after about $20 \mathrm{~s}$. The maximum length of the external hot jet is about $2 \mathrm{~m}$ (no harm distance), i.e. two sizes of the 
enclosure. The maximum length of the pain limit temperature is about $1.5 \mathrm{~m}$. The third degree burn distance changes from zero at about $6 \mathrm{~s}$ to maximum of about $0.5 \mathrm{~m}$ at $15 \mathrm{~s}$. Thus, approaching the fuel cell during this time could present real hazard for people. The "death" zone disappears after about $27 \mathrm{~s}$ when there is air intake into the enclosure (see Fig. 6).

\section{CONCLUSIONS}

The self-extinction of a hydrogen flame in an enclosure with one vent has been simulated for the first time with a full chemistry model, with application of the EDC model for combustion and the RNG theory for turbulence. These are pre-test simulations of experiments planned to be carried out in 2013-2014 as a part of the HyIndoor project (www.hyindoor.eu). The analysis of the numerical experiment assisted in understanding of the self-extinction process. The use of averaged throughout the enclosure parameters during under-ventilated fire can give a good indication of the moment when combustion essentially reduces however it can underestimate the timing when the flame is fully self-extinguished. The pressure peaking phenomenon for jet fires is shown to be more hazardous than for unignited release from the same source, e.g. in this particular experiment the overpressure is about 100 times larger for jet fire scenario (300 $\mathrm{Pa}$ and $3 \mathrm{~Pa}$ for jet fire and unignited jet respectively). The separation distance from the enclosure for this indoor hydrogen fire scenario is about twice of the enclosure size. Contrary to the expectation that gases will flow only out of the enclosure during the process, the simulations demonstrated a complex pattern of flow through the vent in both directions during the selfextinction process. The reason for this "unexpected" phenomenon is the interaction between sustained cold hydrogen leakage, creation of hot combustion products and their cooling after self self-extinction by cold hydrogen jet and heat transfer to the enclosure walls. The results of this study demonstrate the potential of the model to be used as a contemporary hydrogen safety engineering tool for real life applications.

\section{ACKNOWLEDGEMENTS}

The authors would like to express their gratitude to the Fuel Cells and Hydrogen Joint Undertaking for funding this research through the HyIndoor project (grant No. 278534).

\section{REFERENCES}

1. Magnussen, B.F., "Modelling of pollutant formation in gas turbine combustors based on the eddy dissipation concept," Proceedings of the CIMAC Conference, 4-9 June, 1989, Tianjin, China.

2. Yakhot, V., and Orszag, S., "Renormalization group analysis of turbulence. I. Basic theory." Journal of Scientific Computing, 1:3-51 (1986).

3. Bragin, M.V., Makarov, D.V., Molkov, V.V., "Pressure limit of hydrogen spontaneous ignition in a T-shaped channel," Proceedings of the 4th International Conference on Hydrogen Safety, 12-14 September 2011, San Francisco, USA (to be published in International Journal of Hydrogen Energy).

4. Molkov, V., Shentsov, V., and Quintiere, J., "Sustained hydrogen leak concentration in enclosure with one vent," Proceedings of the 7th International Seminar on Fire and Explosion Hazards, Providence, RI, USA, May 2013 (this volume).

5. Brennan, S., Makarov, D., Molkov, V., "Dynamics of flammable hydrogen-air mixture formation in an enclosure with a single vent," Proceedings of the 6th International Seminar on Fire and Explosion Hazards, Leeds, April 2010.

6. Wen, J.X., Xu, B.P., Tam, V.H.Y., "Numerical study on spontaneous ignition of pressurized hydrogen release through a length of tube," Combustion and Flame, 156(11): 2173-2189 (2009).

7. Molkov, V. Fundamentals of Hydrogen Safety Engineering. Free download eBook available at: www.bookboon.com, October 2012. 